\title{
DEPENDENCE OF FUEL CONSUMPTION OF MEDIUM POWER TRACTOR ON DIFFERENT SOIL AND TIRE DEFORMATIONS
}

\author{
Vidas Damanauskas, Aleksandras Velykis, Antanas Satkus \\ Lithuanian Research Centre for Agriculture and Forestry \\ damvid@gmail.com, velykisalex@gmail.com, antanas.satkus@gmail.com
}

\begin{abstract}
Tractors usually are designed to pull the implements in fields. The resistance force of the implement is proportional to the wheel adhesion with soil and depends on the soil conditions, where tractor wheels interact with the soil surface. The part of the tractor's power is lost during the process of interaction between the tires and the soil surface. The tire pressure and vertical wheel load are easily managed parameters, which have an influence on interaction between the tires and the soil surface, the tires and soil deformations and the tractor fuel consumption. Tire deformation is reversible and permissible, but soil deformation is almost irreversible and undesirable. Soil deformation increases the soil density and in this case plants have unfavourable conditions to grow. The studies have shown that the weight of a tractor should be small in wet viscous soil conditions, because then the enlargement ballast weigh increases soil deformation. In this case, the tractor may not be able to develop maximum traction, as its engine energy is used to overcome the moving resistance. Tractor fuel consumption in viscous soil conditions was reduced by reducing soil and tire deformations. It was achieved by doubling the wheels and selecting the air pressure in tires. The aim of this research is to evaluate the energy and environmental aspects of a tractor with single and double wheels to determine the energy efficiency in case of soil and tire deformation.
\end{abstract}

Keywords: inflation pressure, moving resistance, fuel consumption.

\section{Introduction}

The changeable soil composition, hardness and humidity have important influence on the traction performance parameters: tractor's slippage, motion resistance ratio, drawbar power, fuel consumption, tractor's mobility number and productivity results $[1 ; 2]$. According to road conditions it is possible to control their vertical load forces by the tractor's drive-wheels load (ballasting), to select the tire caring area by reducing the tire inflation pressure or using double wheels. Variations in the soil structure and surface roughness affect the variations in the implement resistance and drawbar [3;4].

The tractor slippage is changing widely in the field works and in the same field it depends on the soil features. The tractor ballast weight is used for better tire adhesion to the soil surface. The ballasting and tire inflation pressure are changed for slippage normalization, for that tire deformation and soil deformation change, too. The ballast weight increasing the fuel consumption is reported in many articles [5;6]. The ballast weight increases the tire sinkage and makes deep ruts in the soil [7]. The action to soil is proportional to the tractor mass and tire lug bearing plot. Reducing of the tire pressure increases the bearing contact area with the soil surface. A new generation tires of agricultural tractors are designed as more elastic, more adaptable to the soil surface roughness, which can have better grip on the topsoil [8]. The tire inflation pressure is regarded as an important factor, which affects the tractor field performance such as the draft power, fuel consumption and soil compaction. The soil compaction is a problem, which influences the crop production, growth and the yield reduces noticeable, but it is difficult to assess the correct impact of the factors on the soil productivity losses. The reduction of the tire inflation pressure, at the same tractor mass, makes a bigger contact length and bigger tire rolling resistance, at the same time, a lower wheel radius, hourly fuel consumption and slower speed $[9 ; 10]$. The depth of ruts, higher rolling resistance and fuel consumption occur in more viscous soil. As a result, the soil becomes very compacted, significantly altering the physical properties and it is unfavorable for plants. In general, good soil for crop production contains about 25 percent water, 25 percent air by volume. Wheel traffic reduces pore space, as a result the density of soil increases, poor internal drainage and aeration worsen; it is undesirable from the environmental point of view $[11 ; 12]$.

High resisting forces usually indicate the increased probability for ecological damage, because most of the net energy developed by the engine is transferred into the soil. Also, high resisting forces indicate lower velocity, and thus lower productivity of the tractor aggregate. Many researchers reported that only 50-60\% of the potential of tractive efficiency may be achieved on soft soil, because the power is limited by the rolling resistance or by wheel slip [3; 12]. As a rule, peaty and organic soils 
have very poor traffic ability due to high water content and low dry density [8; 13; 14]. Rolling resistance is one of the most significant mobility parameters. Rolling resistance was investigated by Bekker, Wismer and Luth. It depends mainly on soil and tyre deformation. Rolling resistance influences the value of slip, therefore, determines the wheel slip in connection with rolling resistance and it is important for thrust [12]. We can calculate the depth of ruts, remaining in the wheel track; this depth depends on the soil state and bearing capacity. Soil bearing capacity can be assessed by using different testing methods and the soil parameters also have dependence on the loading conditions. In the WES-method the soil penetration resistance is measured using a standard cone penetrometer [13]. This is rather a simple operation and the analysis of the results is easy. In the Bekker-method the soil constants are calculated from plate sinkage test results, but the analysis of these results are more complicated than in the WES method. The mathematical method, based on soil strength tests, demands the most resources in measuring the soil parameters, and seems more appropriate for scientific programmers than for field applications $[3 ; 15 ; 16]$. Typically, the depth of ruts is determined experimentally $[17 ; 18]$.

In contact with soil, the tire of agricultural machinery leaves a footprint, the size of which depends on the soil type and its physical characteristics, type of tires (stiffness, tread), tire inflation pressure and wheel load $[6 ; 10]$. Footprint area is the portion of the wheel or tire that comes in contact with a supporting surface and has a major role in relation to crop production and the environment [1; 11]. When we decrease the tire pressure, at same time the rolling radius of the wheel is decreased, herewith the mowing speed is lower [10]. Deformation of tires in most cases increase the footprint length, the engine power is lost for a higher rolling resistance. On soft wet soil the rolling resistance and slippage are bigger as a part of total loses $[9 ; 12]$. The problem can be reduced by using the double wheels. The advantages of dual wheels for the agricultural tractor are obvious: more pulling power, reduced compaction of soil, greater fuel efficiency and less wear of the tractor parts. For four-wheel drive tractors, dual tires increased the pull/weight ratio at a given slip level when compared to singles. By the operating with duals instead of singles, the overall tractor efficiency was increased by $15 \%$, while the specific fuel consumption was decreased by averagely $13 \%[4 ; 5 ; 19 ; 20]$. One of the reasons of the advantage is less rolling resistance at the same tire contact plot area compared with single wheels.

\section{Materials and methods}

At the present work the approach was to evaluate fuel consumption loses for the rolling resistance of a tractor with single and double wheels in field. Soil penetration resistance has influence (strong correlation exists) on the vehicle track depth. In this research, the influence of soil and tire deformation as the tractor rolling resistance dependence on convertible tractor tire pressure and wheel doubling in moving without a drawbar is examined. "Penetrologer ML2x-UM-1.21" was used to evaluate soil hardness and water content following the standard procedure (ASABE. 2006a. S313.3 FEB04; ASABE. 2006b. EP542). Measurements of soil deformation were done in the clay loam field prepared for sowing after damping effect of the front and rear wheels with the tire pressure 70, 110, $150,190,230 \mathrm{kPa}$ in the front and rear wheels (Fig. 1).

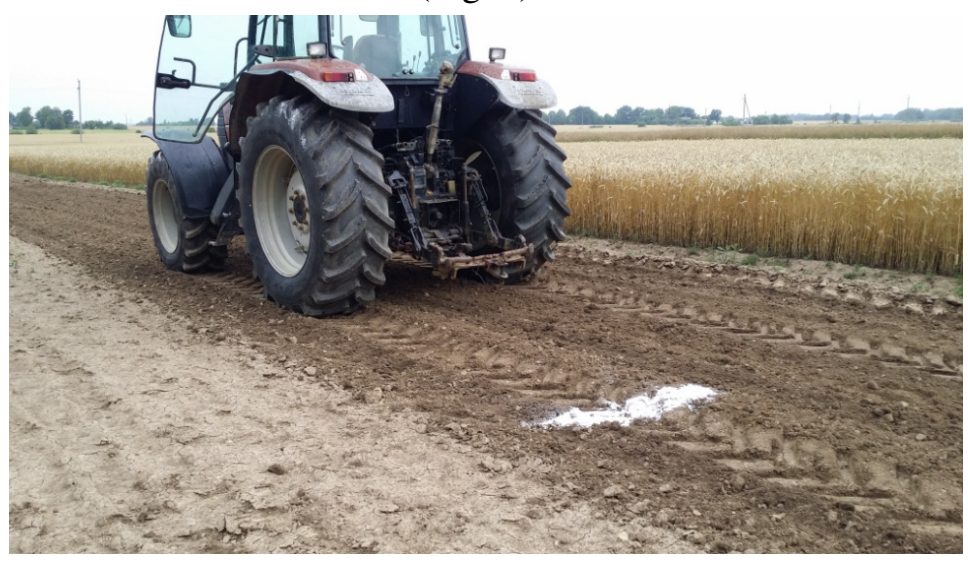

Fig. 1. Field test for measuring soil deformation 
Soil deformation was estimated by measuring the sinkage ruts in the front tire grip lug and after the total front and rear wheel compaction effect. Soil deformation done by rear wheels is calculated:

$$
h_{r}=z-h_{f}
$$

where $z$-wheel sinkage;

$h_{r}$ - vertical distance from the soil surface to the track formed by the rear tire lugs;

$h_{f}-$ vertical distance from the soil surface to the track formed by the front tire lugs.

The tire deformation estimating tests were conducted on gravel road, on a straight $100 \mathrm{~m}$ long horizontal distance. The test was carried out by making all possible variations for the tire inflation pressure $70,110,150,190,230 \mathrm{kPa}$ in the front and rear wheels. For finding the wheel dynamic radiuses the distances were measured how far each of the front and rear wheels travelled during 10 revolutions with disabled front axle. Markers were attached to the front and rear wheels and marks were made on the road for the distances that both front and rear wheel traveled by turning 10 revolutions. The laser gauge Bosch PLR 50 was used to measure the travel distance.

Radius of wheels was estimated by the following equation:

$$
r_{e}=\frac{d_{n}}{2 \pi \cdot n}
$$

where $n$-number of wheel revolutions;

$d_{n}$ - distance of wheel frog;

$n$ - number of revolutions of the wheel.

The tire deformation rate is calculated by the following equation:

$$
\begin{gathered}
\Delta r_{f}=\frac{\left(d_{f(2 x 4)}-2 \pi \cdot r_{0 f}\right)}{2 \pi \cdot H_{f}} \\
\Delta r_{r}=\frac{\left(d_{r(2 x 4)}-2 \pi \cdot r_{0 r}\right)}{2 \pi \cdot H_{r}}
\end{gathered}
$$

where $d_{f(2 \times 4)}$ and $d_{r(2 \times 4)}$ - distances what the front and rear wheels travelled during 10 revolutions with disabled front axle;

$r_{0 f}$ and $r_{0 r}$ - inner radiuses of the front and rear wheels;

$H_{f}$ and $H_{r}$ - height of the front and rear tires.

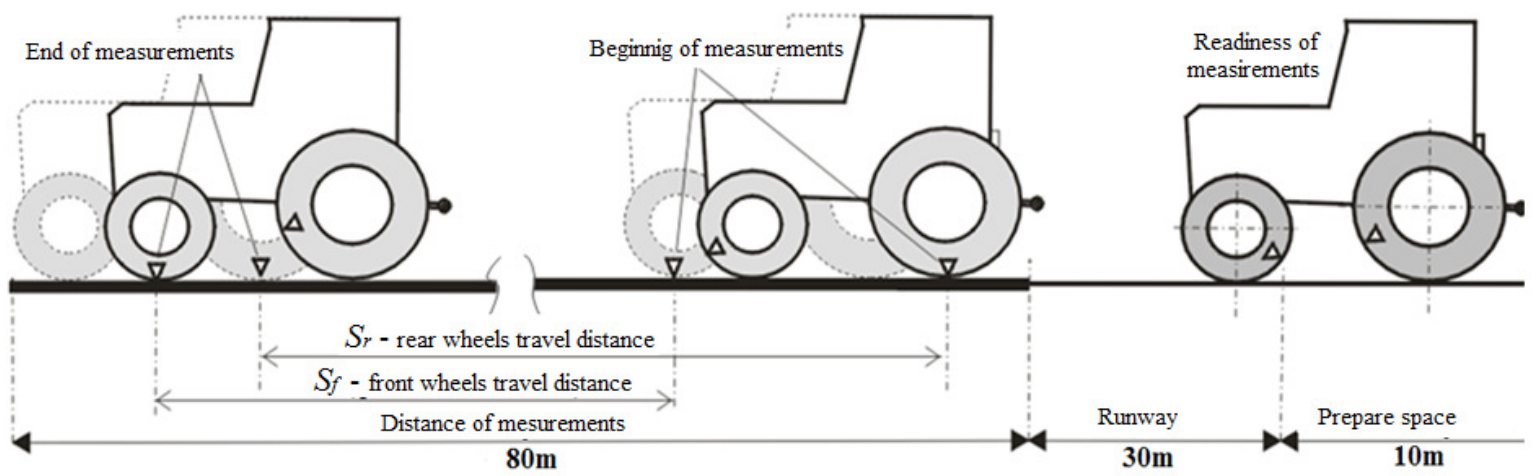

Fig. 2. Measurement scheme of tire deformation estimating tests

Suggest that the dissipated fuel consumption has direct relation with the rolling resistance. The tractor's turbocharged diesel engine speed was fixed as field work at $1500 \pm 10 \mathrm{~s}^{-1}$ and the velocity was about $2.5 \mathrm{~m} \cdot \mathrm{s}^{-1}$, the same tractor mass for each of the conducted treatments was used to obtain the wasted power and the energy loss. The weight of double wheels was estimated and this mass put on the tractor front and rear lift when the tractor was tested in single wheels. Fuel consumption $\left(1 \cdot \mathrm{h}^{-1}\right)$ was measured by VZO 4 OEM fuel flow meter (Aquametro). The tractor was equipped with the data recorder - accumulator SKRT-21 Lite with electronic clock and software SKRT-MANAGER. 
Design sensors of the tractor were used for measuring the engine and ground speeds. The fuel flow meter and tractor sensors were connected in parallel to the installed instrument system SKRT-21 Lite. Calibration of all devices was performed according to standard procedures.

The experimental tests were made on clay loam soil field prepared for sowing (56 ${ }^{\circ}$ '19.92", $\left.24^{\circ} 10^{\prime} 0.76^{\prime \prime}\right)$. Soil moisture at a depth of $10 \mathrm{~cm}$ was $20.6 \pm 1.1 \%$, soil surface $0-10 \mathrm{~cm}$ hardness $0.95 \pm 0.09 \mathrm{MPa}$, weather temperature $18 \pm 2^{\circ} \mathrm{C}$. The tests were carried out by making all combinations of selected tire inflation pressure at the same tractor mass for the given tire deformations. The sizes of doubled wheel rear tires 520/70 R38 and front 420/70 R28 "Firestone" were the same.

\section{Results and discussion}

Various tire deformations were obtained with changing the tire inflation pressure when: tractor mass $-5650 \mathrm{~kg}$; weight distribution front/ rear wheels $-39 / 61 \%$, tractor speed $1,36 \pm 0.01 \mathrm{~m} \mathrm{~s}^{-1}$ without drawbar pull force on gravel road. The tire deformation coefficient was estimated as $\Delta r$. When the tires are not affected by weight load (i.e., not deformed) the coefficient equals to one. The soil deformation was found using a tractor with mass $5650 \mathrm{~kg}$ by measuring the sinkage ruts in the tire grip lug. The soil deformation coefficient was estimated as $\Delta s$ and calculated as division of the distance in disturbed and not disturbed soil surface after the compression effect of the tractor wheels.

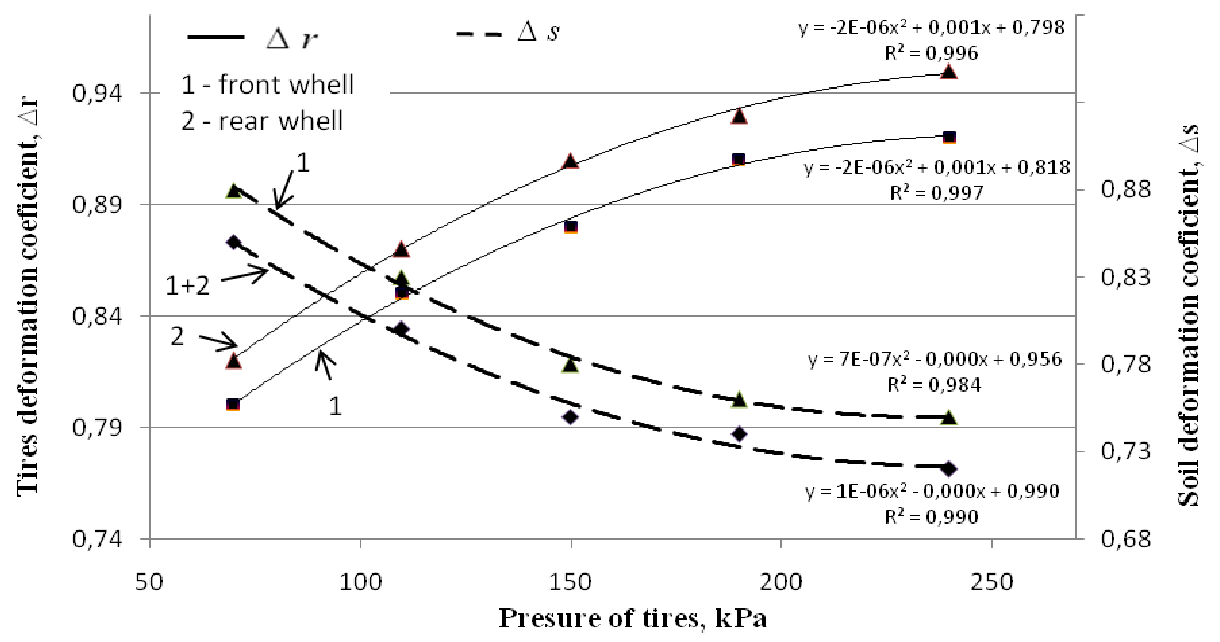

Fig. 3. Single tires and soil deformation coeficient dependence of tire pressure

Figure 3 shows that the tractor front tires were more deformed when the tire inflation pressure in the front and rear tires is equal. However, when the tire inflation pressure was reduced the variation of the rear tire deformation ratio was slightly higher. Tire deformation was the biggest when the tire pressure was the lowest $70 \mathrm{kPa}$. The soil deformation coefficient $\Delta s$ changes depending on the tire pressure. Soil deformation is increasing when the air pressure in the tires is increased. When the tire pressure was the highest $(250 \mathrm{kPa})$, soil deformation was the strongest (coefficient 0.7 ).

For estimating the require energy for a fixed job, the fuel consumption was measured for a tractor travel distance $400 \mathrm{~m}$ leght in field in all cases of selected tire presure and doubling wheels (Fig. 4).

Figure 4 shows fuel consumption energy waste by the tractor with single wheels on soft, prepared for sowing deformable soil. Fuel consumption was the highest when the tyre and soil deformation, i.e. the rolling resistance was the biggest.

The investigation showed that the rolling resistance and fuel consumption were lower when the soil and tire deformation was reduced (Fig.5). In case when double wheels are used, the deformation of tires was rather less with comparison to single wheel tires at the same tire presure. Soil deformation depends on the tire contact area. The mesurements show that the footprint of a single wheel at minimal presure was the same as for double wheels at higer tire presure. The contact area of tire 520/70R38 "Firestone" footprint varied from 0.42 to $0.25 \mathrm{~m}^{2}$ when the tire pressure was changed from 70 to $240 \mathrm{kPa}$. The contact area of the double tire footprint varied from 0.45 to $0.75 \mathrm{~m}^{2}$, when the tire pressure was changed from 240 to $70 \mathrm{kPa}$. 


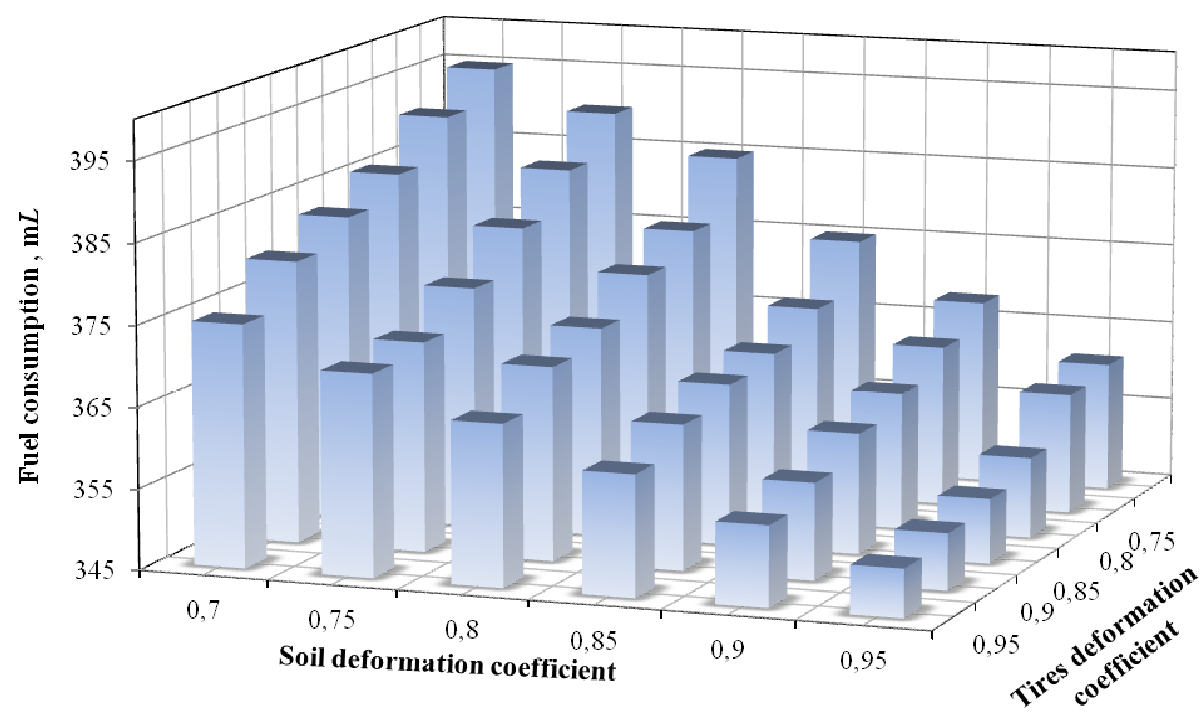

Fig. 4. Fuel consumption of tractor with single wheels dependence on different tire and soil deformation for fixed travel distance

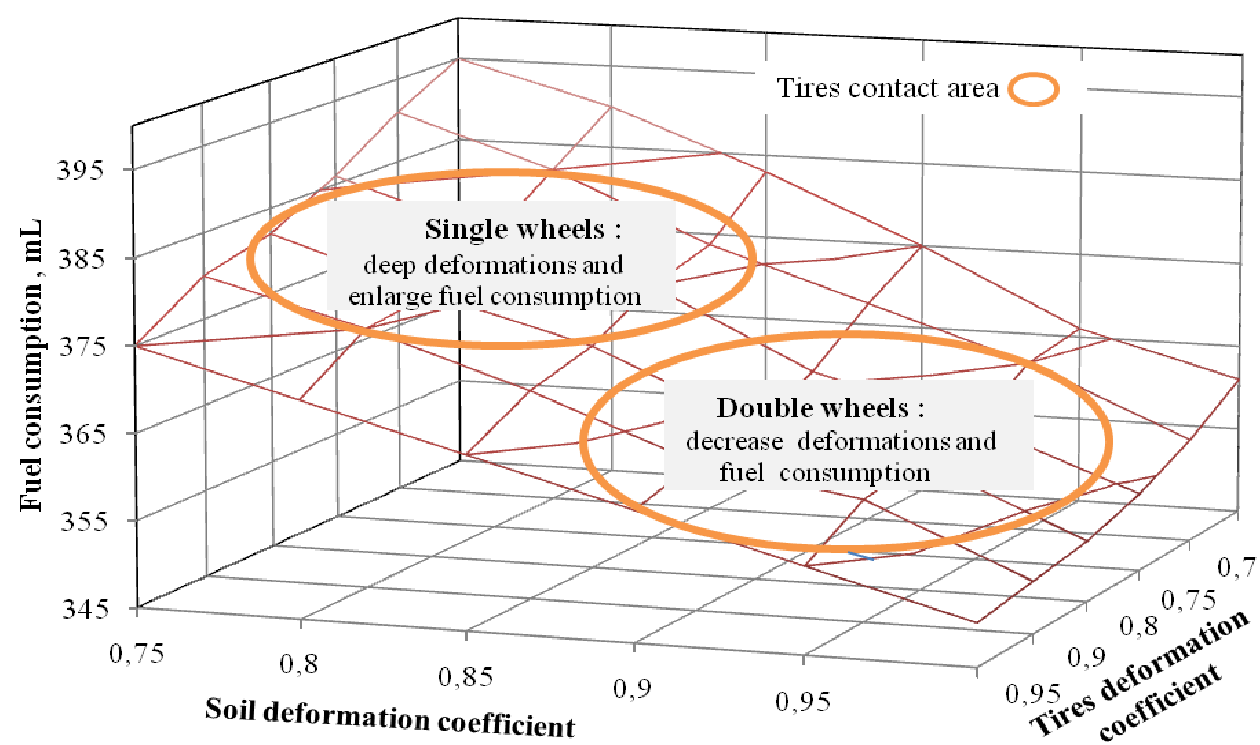

Fig. 5. Fuel consumption with single and double wheels at the same contact area of tires

Figure 5 shows that fuel consumption depends on the tire contact area caused by the air pressure and wheel doubling. The fuel consumption varied from 370 to $390 \mathrm{ml}$, when single wheels were used and the fuel consumption ranged from 350 to $370 \mathrm{ml}$, when double wheels were used. The fuel consumption was bigger about $40 \mathrm{ml}$ for fixed tests distance when using single wheels at minimal $(70 \mathrm{kPa})$ tire presure compared with double wheels at higer $(240 \mathrm{kPa})$ tire presure. This is not a really large reduction of the fuel consumption but wheel doubling can effectively reduce the soil compaction, what leads to positive crop production and yield increase.

\section{Conclusions}

The results of this study may provide helpful indications for the appropriate choice of the tractor configuration, with view to optimising the drive wheels configurations on soft soils, thereby reducing the fuel consumption in field operations.

1. Based on the results, it is considered that the lowest harmful impact to soil deformations was with the lowest permissible tire pressure. The biggest rut formation was observed when the tire pressure was $240 \mathrm{kPa}$ and the soil deformation coefficient was 0.7 . 
2. Selecting the air pressure in the single tires at the constant tractor weight and travel distance has influence on the fuel consumption, which warred from 370 to $390 \mathrm{ml}$ in the field of the tractor movement without drawbar.

3. The tractor's with double wheels, to compare with single wheels at the same tire contact area, which is accessible by changing the tire pressure, fuel consumption decreased from 390 to $350 \mathrm{ml}$ for the same fixed travel distance.

\section{References}

1. Elwaleed A. K., Yahya A., Zohadie M., Ahmad D., Kheiralla A. F. Effect of inflation pressure on motion resistance ratio of a high-lug agricultural tyre, Journal of Terramechanics, vol. 43(2), 2006, pp. 69-84.

2. Taghavifar H., Mardani A. Investigating the velocity, inflation pressure and vertical load on rolling resistance of a radial ply tire, Journal of Terramechanics, vol. 50, 2013, pp. 99-106.

3. Bekker M. G. Introduction to terrain-vehicle systems. University of Michigan Press, Ann Arbor, $1969,846 \mathrm{p}$.

4. Way T. R., Kishimoto T. Interface pressures of a tractor drive tyre on structured and loose soils. Biosystems Engineering, vol. 87(3), 2004, pp. 375-386

5. Ashok Kumar A., V.K. Tewari, Chanchal Gupta, C.M. Pareek. A device to measure wheel slip to improve the fuel efficiency of off road vehicles. Journal of Terramechanics, vol. 70, 2017, pp.1-11.

6. Damanauskas V. The improvement of the medium power MFWD tractor performance and environmental protection in the assessment of tires deformations. Summary of the Doctoral Dissertation, Aleksandras Stulginskis University, Lithuania, 2015.

7. Ju S. Nam, Young J. Park, Kyeong U. Kim. Determination of rating cone index using wheel sinkage and slip. Journal of Terramechanics, vol. 47, 2010, pp. 243-248

8. Erickson L., Larsen W., Rust S. Four-Wheel Drive Tractor Axle and Drawbar Horsepower: Field Evaluation and Analysis. ASAE Paper No. 82-1057, 1982, ASAE, St. Joseph, Michigan.

9. Damanauskas V., Janulevičius A. The Influence of Driving Double Wheels to the Slippage of Tractor // Mechanics, 2009: proceedings of 14th international conference, April 2-3 2009, Kaunas, Lithuania /ISSN 1822-2951. 2009, pp. 83-87.

10. Perdok U.D., Kroesbergen B. Cone index as a function of soil moisture and pore volume. Proceedings of the 13th International Conference of the ISTVS. Munich, Germany 1999, September 14-17, pp. 5-12.

11. Arvidsson J., Keller T. Soil stress as affected by wheel load and tyre inflation pressure, Soil and Tillage Research, vol. 96, 2007, pp. 284-291.

12. Battiato A., Diserens E. Tractor traction performance simulation on differently textured soils and validation: A basic study to make traction and energy requirements accessible to the practice, Soil and Tillage Research, vol. 166, 2017, pp.18-32

13. Maclaurin E. B. The use of mobility numbers to predict the tractive performance of wheeled and tracked vehicles in soft cohesive soils. Proceedings of the 7th European ISTVS Conference, Ferrara, Italy, 8-10 October 1997, pp. 391-398.

14. Wang Z., Domier K.W. Prediction of Drawbar Performance for a Tractor with Dual Tires. Transactions of the ASAE, vol. 32, No. 5, 1989, St.Joseph, Michigan.

15. Hambleton J.P., Dresher A. Development of improved test rolling methods for roadway embankment construction. Final Report MN/RC 2008-08. Minesota Department of Transportation, St. Paul, MN.

16. Lamande' M., Schjønning P. Transmission of vertical stress in a real soil profile. Part II: Effect of tyre size, inflation pressure and wheel load, Soil and Tillage Research, vol. 114, 2011, pp. 71-77.

17. Affleck RT. Disturbance measurements from off-road vehicles on seasonal terrain. Technical report ERDC/CRREL TR-05-12. US Army Corps of Engineers. 2005. Vicksberg, MISS. USA.

18. Grisso R., Taylor R., Way T., Bashford L. Tractive Performance of $18.4 R 46$ and 18.4 R42 Radial Tractor Tires. ASAE Paper No. 91- 1589, 1991, ASAE, St. Joseph, Michigan.

19. Available at: hppt://gs.elaba.lt/object/elaba:12017632/12017632.pdf

20. Tiwari V. K., Pandey K. P., Pranav, P. K. A review on traction prediction equations. Journal of Terramechanics, vol. 47, 2010, pp. 191-199. 